CARPATHIAN J. MATH.

Volume 37 (2021), No. 2,

Pages 145 - 160
Online version at https : //www . carpathian. cunbm . utcluj.ro/

Print Edition: ISSN 1584 - 2851; Online Edition: ISSN 1843 - 4401

DOI: https://doi.org/10.37193/CJM.2021.02.01

Dedicated to Prof. Ioan A. Rus on the occasion of his $85^{\text {th }}$ anniversary

\title{
A novel iterative approach for solving common fixed point problems in Geodesic spaces with convergence analysis
}

\author{
THANATPORN BANTAOJAI ${ }^{1}$, CHANCHAL GARODIA ${ }^{2}$, IZHAR UdDIN ${ }^{2}$, \\ NUTTAPOL PAKKARANANG ${ }^{3}$ and PANU YIMMUANG ${ }^{4, \dagger}$
}

\begin{abstract}
In this paper, we introduce a new iterative method for nonexpansive mappings in CAT $(\kappa)$ spaces. First, the rate of convergence of proposed method and comparison with recently existing method is proved. Second, strong and $\Delta$-convergence theorems of the proposed method in such spaces under some mild conditions are also proved. Finally, we provide some non-trivial examples to show efficiency and comparison with many previously existing methods.
\end{abstract}

\section{INTRODUCTION}

It was M. Gromov [9] who coined the term $\operatorname{CAT}(\kappa)$ to denote a distinguished class of geodesic metric spaces with curvature bounded above by $\kappa \in \mathbb{R}$. CAT $(\kappa)$ spaces can be understood as a generalization of Riemannian manifolds with bounded sectional curvature. In recent years, CAT $(\kappa)$ spaces have attracted the attention of many young researchers owing to their important role in different aspects of geometry. A very thorough discussion on these spaces and the role they play in geometry can be found in the book by M. R. Bridson and A. Haefliger [4].

In 2003-2004, Kirk who noticed the richness of geometry of CAT $(\kappa)$ spaces and introduced the fixed point theory in $\operatorname{CAT}(\kappa)$ spaces $[12,13]$. Following this, different authors produced a series of work mainly focussing on CAT(0) spaces (see e.g., $[5-7,14,15,19,23,26]$ ). Also, it is worth mentioning that any CAT $(\kappa)$ space is a CAT $\left(\kappa^{\prime}\right)$ space for every $\kappa^{\prime} \geq \kappa$ (see in [4]). So, the results of CAT(0) space holds good for any CAT $(\kappa)$ space with $\kappa \leq 0$. Further, $\mathrm{CAT}(\kappa)$ spaces for $\kappa>0$, were studied by some authors (see for instance $[8,10,18,20$ $22,24,27])$ and many authors have introduced various iteration processes for approximating fixed points in CAT $(\kappa)$ spaces. In 2011, B. Piatek [22] proved that an iterative sequence generated by the Halpern algorithm converges to a fixed point in the complete CAT $(\kappa)$ spaces. Further, in 2012, He et al. [10] showed that the famous Mann algorithm converges to a fixed point in complete CAT $(\kappa)$ spaces and B. Panyanak [20] proved the convergence of Ishikawa iteration for multivalued mappings in CAT $(\kappa)$ spaces.

Very recently, Thounthong et al. [28] introduced the following modified iteration process to approximate common fixed point of two nonexpansive mappings.

Let $C$ be a non-empty closed convex subset of a complete CAT $(\kappa)$ space $X$ and $T, S: K \rightarrow$ $K$ be two nonexpansive mappings. Suppose that a sequence $\left\{c_{n}\right\}$ is generated iteratively

Received: 15.10.2020. In revised form: 16.04.2021. Accepted: 22.04.2021

2010 Mathematics Subject Classification. 47H09, 47H10, 65K15.

Key words and phrases. CAT $(\kappa)$ spaces; Iterative method; Nonexpansive mappings; Common fixed point.

Corresponding author: † Panu Yimmuang; panu.y@sut.ac.th 
by:

$$
\left\{\begin{array}{l}
c_{1} \in K \\
a_{n}=\left(1-\alpha_{n}\right) c_{n} \oplus \alpha_{n} T c_{n} \\
b_{n}=\left(1-\beta_{n}\right) a_{n} \oplus \beta_{n} S a_{n} \\
c_{n+1}=\left(1-\gamma_{n}\right) T a_{n} \oplus \gamma_{n} S b_{n}
\end{array}\right.
$$

where $\left\{\alpha_{n}\right\},\left\{\beta_{n}\right\}$ and $\left\{\gamma_{n}\right\}$ are sequences in $(0,1)$.

Motivated by (1.1) we propose the following iteration to locate the common fixed point of $T$ and $S$.

$$
\left\{\begin{array}{l}
x_{1} \in K \\
z_{n}=\left(1-\alpha_{n}\right) x_{n} \oplus \alpha_{n} T x_{n} \\
x_{n+1}=S\left(T\left(\left(1-\beta_{n}\right) z_{n} \oplus \beta_{n} S z_{n}\right)\right)
\end{array}\right.
$$

where $\left\{\alpha_{n}\right\}$ and $\left\{\beta_{n}\right\}$ are sequences in $(0,1)$.

In this paper, we propose a new iteration process for two nonexpansive mappings in complete $\mathrm{CAT}(\kappa)$ spaces. We prove that our proposed iteration process converges faster than iteration process (1.1) for contractive like mappings. We have also constructed a an example to support our claim. Further, we prove strong and $\Delta$-convergence results involving the proposed iteration process under some conditions. We finally provide numerical experiments of two non-trivial examples to demonstrate the speed of convergence of iteration process (1.2) with existing iterations which further supports our main results.

\section{PRELIMINARIES}

Let $(X, d)$ be a metric space. A geodesic path joining $x \in X$ to $y \in X$ (or, more briefly, a geodesic from $\mathrm{x}$ to $\mathrm{y}$ ) is a map c from a closed interval $[0, l] \subset \mathbb{R}$ to $X$ such that $c(0)=x$, $c(l)=y$ and $d\left(c(t), c\left(t^{\prime}\right)\right)=\left|t-t^{\prime}\right|$ for all $t, t^{\prime} \in[0, l]$. In particular, $\mathrm{c}$ is an isometry and $d(x, y)=l$. The image $\alpha$ of $c$ is called a geodesic (or metric) segment joining $\mathrm{x}$ and $\mathrm{y}$. We say that $X$ is $(i)$ a geodesic space if any two points of $X$ are joined by a geodesic, and ( $i i)$ uniquely geodesic if there is exactly one geodesic joining $x$ and $y$ for each $x, y \in X$, which we will denote by $[x, y]$. This means that $z \in[x, y]$ if and only if there exists $\alpha \in[0,1]$ such that $d(x, z)=(1-\alpha) d(x, y)$ and $d(y, z)=\alpha d(x, y)$. In this case, we write $z=\alpha x \oplus(1-\alpha) y$. The space $(X, d)$ is said to be a geodesic space (D-geodesic space) if every two points of $X$ (every two points of distance smaller than $\mathrm{D}$ ) are joined by a geodesic, and $X$ is said to be uniquely geodesic (D-uniquely geodesic) if there is exactly one geodesic joining $x$ and $y$ for each $x, y \in X$ (for $x, y \in X$ with $d(x, y)<D$ ). A subset $K$ of $X$ is said to be convex if $K$ includes every geodesic segment joining any two of its points. The set $K$ is said to be bounded if

$$
\operatorname{diam}(K):=\sup \{d(x, y): x, y \in K\}<\infty .
$$

Denote $F(T)=\{x \in K: T x=x\}$ is the set of fixed points of mapping $T$.

Definition 2.1. Given $k \in \mathbb{R}$, we denote by $M_{\kappa}^{n}$ the following metric spaces:

(i) if $\kappa=0$ then $M_{0}^{n}$ is the Euclidean space $\mathbb{E}^{n}$;

(ii) if $\kappa>0$ then $M_{\kappa}^{n}$ is obtained from the spherical space $\mathbb{S}^{n}$ by multiplying the distance function by the constant $\frac{1}{\sqrt{\kappa}}$;

(iii) if $\kappa<0$ then $M_{\kappa}^{n}$ is obtained from the hyperbolic space $\mathbb{H}^{n}$ by multiplying the distance function by the constant $\frac{1}{\sqrt{-\kappa}}$. 
A geodesic triangle $\Delta(x, y, z)$ in the metric space $(X, d)$ consists of three points $x, y, z$ in $X$ (the vertices of $\Delta$ ) and three geodesic segments between each pair of vertices (the edges of $\Delta$. We write $p \in \Delta(x, y, z)$ when $p \in[x, y] \cup[y, z] \cup[z, x]$. A comparison triangle for a geodesic triangle $\Delta(x, y, z)$ in $(X, d)$ is a triangle $\Delta(\bar{x}, \bar{y}, \bar{z})$ in $M_{\kappa}^{2}$ such that

$$
d(x, y)=d_{M_{\kappa}^{2}}(\bar{x}, \bar{y}), d(x, z)=d_{M_{\kappa}^{2}}(\bar{x}, \bar{z}) \text { and } d(z, x)=d_{M_{\kappa}^{2}}(\bar{z}, \bar{x}) .
$$

If $\kappa \leq 0$ then such a comparison triangle always exists in $M_{\kappa}^{2}$. If $\kappa>0$ then such a triangle exists whenever $d(x, y)+d(y, z)+d(z, x)<2 D_{\kappa}$, where $D_{\kappa}=\frac{\pi}{\sqrt{\kappa}}$ A point $\bar{p} \in[\bar{x}, \bar{y}]$ is called a comparison point for $p \in[x, y]$ if $d(x, p)=d(\bar{x}, \bar{p})$.

A geodesic triangle $\Delta(x, y, z)$ in $X$ is said to satisfy the $C A T(\kappa)$ inequality if for any $p, q \in$ $\Delta(x, y, z)$ and for their comparison points $\bar{p}, \bar{q} \in \Delta(\bar{x}, \bar{y}, \bar{z})$, one has

$$
d(p, q) \leq d_{M_{\kappa}^{2}}(\bar{p}, \bar{q}) .
$$

Now, we recall the following important lemmas which will be useful in our subsequent discussion.

Lemma 2.1. [4] Let $(X, d)$ be a $C A T(\kappa)$ space and let $K$ be a closed and $\pi$-convex subset of $X$. Then for each point $x \in X$ such that $d(x, K)<\frac{\pi}{2}$, there exists a unique point $y \in K$ such that $d(x, y)=d(x, K)$.

Lemma 2.2. [17] Let $(X, d)$ be a $C A T(1)$ space. Then there is a constant $M>0$ such that

$$
d^{2}(x, t y \oplus(1-t) z) \leq t d^{2}(x, y)+(1-t) d^{2}(x, z)-\frac{M}{2} t(1-t) d(y, z)
$$

for any $t \in[0,1]$ and any point $x, y, z \in X$ such that $d(x, y) \leq \frac{\pi}{4}, d(x, z) \leq \frac{\pi}{4}$ and $d(y, z) \leq \frac{\pi}{2}$.

Let $\left\{x_{n}\right\}$ be a bounded sequence in a $\operatorname{CAT}(\kappa)$ space $(X, d)$. For $x \in X$, we set

$$
r\left(x,\left\{x_{n}\right\}\right)=\limsup _{n \rightarrow \infty} d\left(x,\left\{x_{n}\right\}\right) .
$$

The asymptotic radius $r\left(\left\{x_{n}\right\}\right)$ of $\left\{x_{n}\right\}$ is given by

$$
r\left(\left\{x_{n}\right\}\right)=\inf \left\{r\left(x,\left\{x_{n}\right\}\right): x \in X\right\},
$$

and the asymptotic center $A\left(\left\{x_{n}\right\}\right)$ of $\left\{x_{n}\right\}$ is the set

$$
A\left(\left\{x_{n}\right\}\right)=\left\{x \in X: r\left(x,\left\{x_{n}\right\}\right)=r\left(\left\{x_{n}\right\}\right)\right\} .
$$

Definition 2.2. $[14,16]$ A sequence $\left\{x_{n}\right\}$ in $X$ is said to $\Delta$-converge to $x \in X$ if $x$ is the unique asymptotic center of $\left\{u_{n}\right\}$ for every subsequence $\left\{u_{n}\right\}$ of $\left\{x_{n}\right\}$. In this case we write $\Delta-\lim x_{n}=x$ and call $x$ the $\Delta$-limit of $\left\{x_{n}\right\}$.

Lemma 2.3. [10] Let $(X, d)$ be a complete CAT(1) space and let $K$ be a non-empty subset of $X$. Suppose that the sequence $\left\{x_{n}\right\}$ in $X$ is Fejer monotone with respect to $K$ and the asymptotic radius $r\left(\left\{x_{n}\right\}\right)$ of $\left\{x_{n}\right\}$ is lees than $\frac{\pi}{2}$. If any $\Delta$-cluster point $x$ of $\left\{x_{n}\right\}$ belongs to $K$, then $\left\{x_{n}\right\}$ $\Delta$-converges to a point in $K$.

Lemma 2.4. [10] Let $(X, d)$ be a complete $C A T(1)$ space and let $p \in X$. Suppose that the sequence $\left\{x_{n}\right\}$ in $X \Delta$-converges to $x$ such that $r\left(p,\left\{x_{n}\right\}\right)<\frac{D_{k}}{2}$. then

$$
d(x, p) \leq \liminf _{n \rightarrow \infty} d\left(x_{n}, p\right) .
$$

Definition 2.3. Let $(X, d)$ be a metric space and $K$ be its nonempty subset. Then $T: K \rightarrow$ $K$ is called semi-compact if for a sequence $x_{n}$ in $K$ with $\lim _{n \rightarrow \infty} d\left(x_{n}, T x_{n}\right)=0$, there exist a subsequence $x_{n_{k}}$ of $x_{n}$ such that $x_{n_{k}} \rightarrow p \in K$. 
In 1972, Zamfirescu [29] introduced Zamfirescu mappings which serves as an important generalization for Banach contraction principle [1]. In 2004, Berinde [2] gave a more general class of mappings known as quasi-contractive mappings. Following this, Imoru and Olantiwo [11] gave the following definition:

Definition 2.4. A mapping $T: K \rightarrow K$ is known as contractive-like mapping if there exists a strictly increasing and continuous function $\varphi:[0, \infty) \rightarrow[0, \infty)$ with $\varphi(0)=0$ and a constant $\delta \in[0,1)$ such that for all $x, y \in K$, we have

$$
\|T x-T y\| \leq \delta\|x-y\|+\varphi(\|x-T x\|) .
$$

Clearly, the class of contractive-like mappings is wider than the class of quasi-contractive mappings. [3].

Recall that the following definitions about the rate of convergence were given by Berinde

Definition 2.5. Let $\left\{a_{n}\right\}$ and $\left\{b_{n}\right\}$ be two real sequences converging to $a$ and $b$ respectively.

Then, $\left\{a_{n}\right\}$ converges faster then $\left\{b_{n}\right\}$ if $\lim _{n \rightarrow \infty} \frac{\left\|a_{n}-a\right\|}{\left\|b_{n}-b\right\|}=0$.

Definition 2.6. Let $\left\{u_{n}\right\}$ and $\left\{v_{n}\right\}$ be two fixed point iteration processes converging to the same fixed point $p$. If $\left\{a_{n}\right\}$ and $\left\{b_{n}\right\}$ are two sequences of positive numbers converging to zero such that $\left\|u_{n}-p\right\| \leq a_{n}$ and $\left\|v_{n}-p\right\| \leq b_{n}$ for all $n \geq 1$, then we say that $\left\{u_{n}\right\}$ converges faster than $\left\{v_{n}\right\}$ to $p$ if $\left\{a_{n}\right\}$ converges faster then $\left\{b_{n}\right\}$.

\section{RATE OF CONVERGENCE}

In this section, we prove that our proposed iteration process (1.2) is having a better rate of convergence than (1.1) for contractive-like mappings.

Theorem 3.1. Let $T$ and $S$ be two contractive-like mappings defined on a nonempty, closed, convex subset $K$ of a complete $C A T(1)$ space $(X, d)$ such that $F:=F(T) \cap F(S) \neq \emptyset$. If $\left\{x_{n}\right\}$ is a sequence defined by (1.2), then $\left\{x_{n}\right\}$ converges faster than the iterative algorithm (1.1)

Proof. As, $\left\{\alpha_{n}\right\},\left\{\beta_{n}\right\}$ and $\left\{\gamma_{n}\right\}$ are sequences in $(0,1)$, we can find $\eta, \varsigma \in \mathbb{R}$ such that $0<\eta \leq \alpha_{n}, \beta_{n}, \gamma_{n} \leq \varsigma<1$ for all $n \in \mathbb{N}$.

From (1.2), for any $p \in F$, we have

$$
\begin{aligned}
d\left(z_{n}, p\right) & =d\left(\left(1-\alpha_{n}\right) x_{n} \oplus \alpha_{n} T x_{n}, p\right) \\
\leq & \left(1-\alpha_{n}\right) d\left(x_{n}, p\right)+\alpha_{n} \delta d\left(x_{n}, p\right) \\
& =\left(1-(1-\delta) \alpha_{n}\right) d\left(x_{n}, p\right) ;
\end{aligned}
$$

and

$$
\begin{aligned}
d\left(x_{n+1}, p\right) & =d\left(S\left(T\left(\left(1-\beta_{n}\right) z_{n} \oplus \beta_{n} S z_{n}\right)\right), p\right) \\
& \leq \delta d\left(T\left(\left(1-\beta_{n}\right) z_{n} \oplus \beta_{n} S z_{n}, p\right)\right) \\
& \leq \delta^{2} d\left(\left(1-\beta_{n}\right) z_{n} \oplus \beta_{n} S z_{n}, p\right) \\
& \leq \delta^{2}\left(\left(1-\beta_{n}\right) d\left(z_{n}, p\right)+\beta_{n} d\left(S z_{n}, p\right)\right) \\
& \leq \delta^{2}\left(1-(1-\delta) \beta_{n}\right) d\left(z_{n}, p\right) \\
& \leq \delta^{2}\left(1-(1-\delta) \beta_{n}\right)\left(1-(1-\delta) \alpha_{n}\right) d\left(x_{n}, p\right) \\
& \cdot \\
& \cdot \\
& \leq \delta^{2 n}(1-(1-\delta) \varsigma)^{n}(1-(1-\delta) \varsigma)^{n} d\left(x_{1}, p\right) .
\end{aligned}
$$

From (1.1), we get

$$
\begin{aligned}
d\left(a_{n}, p\right) & =d\left(\left(1-\alpha_{n}\right) c_{n} \oplus \alpha_{n} T c_{n}, p\right) \\
& \leq\left(1-\alpha_{n}\right) d\left(c_{n}, p\right)+\alpha_{n} d\left(T c_{n}, p\right) \\
& =\left(1-(1-\delta) \alpha_{n}\right) d\left(c_{n}, p\right)
\end{aligned}
$$




$$
\begin{aligned}
d\left(b_{n}, p\right) & =d\left(\left(1-\beta_{n}\right) a_{n} \oplus \beta_{n} S a_{n}, p\right) \\
\leq & \left(1-\beta_{n}\right) d\left(a_{n}, p\right)+\beta_{n} d\left(S a_{n}, p\right) \\
\leq & \left(1-(1-\delta) \beta_{n}\right)\left(1-(1-\delta) \alpha_{n}\right) d\left(c_{n}, p\right)
\end{aligned}
$$

and

$$
\begin{aligned}
d\left(c_{n+1}, p\right) & =d\left(\left(1-\gamma_{n}\right) T a_{n} \oplus \gamma_{n} S b_{n}, p\right) \\
\leq & \left(1-\gamma_{n}\right) d\left(T a_{n}, p\right)+\gamma_{n} d\left(S b_{n}, p\right) \\
\leq & \delta\left(\left(1-\gamma_{n}\right) d\left(a_{n}, p\right)+\gamma_{n} d\left(b_{n}, p\right)\right) \\
& =\delta\left(1-(1-\delta) \gamma_{n}\right)\left(1-(1-\delta) \beta_{n}\right)\left(1-(1-\delta) \alpha_{n}\right) d\left(c_{n}, p\right) \\
& \cdot \\
& \cdot \\
& \leq \delta^{n}(1-(1-\delta) \varsigma)^{n}(1-(1-\delta) \varsigma)^{n}(1-(1-\delta) \varsigma)^{n} d\left(c_{1}, p\right) .
\end{aligned}
$$

Now, since $\delta, \varsigma<1$, we have $1-(1-\delta) \varsigma)<1$. So,

$$
d\left(x_{n+1}, p\right) \leq \delta^{2 n} d\left(x_{1}, p\right) \text { and } d\left(c_{n+1}, p\right) \leq \delta^{n} d\left(c_{1}, p\right) .
$$

Let $b_{n}=\delta^{2 n} d\left(x_{1}, p\right)$ and $a_{n}=\delta^{n} d\left(c_{1}, p\right)$, then

$$
\begin{aligned}
\frac{b_{n}}{a_{n}} & =\frac{\delta^{2 n} d\left(x_{1}, p\right)}{\delta^{n} d\left(c_{1}, p\right)} \\
& \rightarrow 0 \text { as } n \rightarrow \infty .
\end{aligned}
$$

Hence in view of Definitions 2.5 and 2.6, $\left\{x_{n}\right\}$ converges faster than $\left\{c_{n}\right\}$.

Now, we present a example of a contractive-like mapping which is not a contraction.

Example 3.1. Let $X=\mathbb{R}$ and $K=[0,6]$. Let $T: K \rightarrow K$ be a mapping defined as

$$
T x= \begin{cases}\frac{x}{5} & x \in[0,3) \\ \frac{x}{10} & x \in[3,6] .\end{cases}
$$

Proof. Clearly $x=0$ is the fixed point of $T$. First, we prove that $T$ is a contractive-like mapping but not a contraction. Since $T$ is not continuous at $x=3 \in[0,6]$, so $T$ is not a contraction. We show that $T$ is a contractive-like mapping. For this, define $\varphi:[0, \infty) \rightarrow$ $[0, \infty)$ as $\varphi(x)=\frac{x}{8}$. Then, $\varphi$ is a strictly increasing as well as continuous function. Also, $\varphi(0)=0$.

We need to show that

$$
\|T x-T y\| \leq \delta\|x-y\|+\varphi(\|x-T x\|)
$$

for all $x, y \in[0,6]$ and $\delta$ is a constant in $[0,1)$.

Before going ahead, let us note the following. When $x \in[0,3)$, then

$$
\|x-T x\|=\left\|x-\frac{x}{5}\right\|=\frac{4 x}{5}
$$

and

$$
\varphi\left(\frac{4 x}{5}\right)=\frac{x}{10}
$$

Similarly, when $x \in[3,6]$, then

$$
\|x-T x\|=\left\|x-\frac{x}{10}\right\|=\frac{9 x}{10}
$$


and

$$
\varphi\left(\frac{9 x}{10}\right)=\frac{9 x}{80}
$$

Consider the following cases:

Case A: Let $x, y \in[0,3)$, then using (3.3) we get

$$
\begin{aligned}
\|T x-T y\| & =\left\|\frac{x}{5}-\frac{y}{5}\right\| \\
& \leq \frac{1}{5}\|x-y\| \\
& \leq \frac{1}{5}\|x-y\|+\frac{x}{10} \\
& =\frac{1}{5}\|x-y\|+\varphi\left(\frac{4 x}{5}\right) \\
& =\frac{1}{5}\|x-y\|+\varphi(\|x-T x\|) .
\end{aligned}
$$

So $(A)$ is satisfied with $\delta=\frac{1}{5}$.

Case B: Let $x \in[0,3)$ and $y \in[3,6]$ then using (3.3) we get

$$
\begin{aligned}
\|T x-T y\| & =\left\|\frac{x}{5}-\frac{y}{10}\right\| \\
& =\left\|\frac{x}{10}+\frac{x}{10}-\frac{y}{10}\right\| \\
& \leq \frac{1}{10}\|x-y\|+\left\|\frac{x}{10}\right\| \\
& \leq \frac{1}{5}\|x-y\|+\varphi\left(\frac{4 x}{5}\right) \\
& =\frac{1}{5}\|x-y\|+\varphi(\|x-T x\|) .
\end{aligned}
$$

So $(A)$ is satisfied with $\delta=\frac{1}{5}$.

Case C: Let $x \in[3,6]$ and $y \in[0,3)$ then using (3.4) we get

$$
\begin{aligned}
\|T x-T y\| & =\left\|\frac{x}{10}-\frac{y}{5}\right\| \\
& =\left\|\frac{x}{5}-\frac{x}{10}-\frac{y}{5}\right\| \\
& \leq \frac{1}{5}\|x-y\|+\left\|\frac{x}{10}\right\| \\
& \leq \frac{1}{5}\|x-y\|+\left\|\frac{9 x}{80}\right\| \\
& =\frac{1}{5}\|x-y\|+\varphi(\|x-T x\|) .
\end{aligned}
$$

So $(A)$ is satisfied with $\delta=\frac{1}{5}$.

Case D: Let $x, y \in[3,6]$ then using (3.4) we get

$$
\begin{aligned}
\|T x-T y\| & =\left\|\frac{x}{10}-\frac{y}{10}\right\| \\
& \leq \frac{1}{10}\|x-y\|+\left\|\frac{9 x}{80}\right\| \\
& \leq \frac{1}{5}\|x-y\|+\left\|\frac{9 x}{80}\right\| \\
& =\frac{1}{5}\|x-y\|+\varphi(\|x-T x\|) .
\end{aligned}
$$


So $(A)$ is satisfied with $\delta=\frac{1}{5}$.

Consequently, $(A)$ is satisfied for $\delta=\frac{1}{5}$ and $\varphi(x)=\frac{x}{8}$ in all the possible cases. Thus, $T$ is a contractive-like mapping. Similarly, define $S: K \rightarrow K$ as

$$
S x= \begin{cases}\frac{x}{6} & x \in[0,4) \\ \frac{x}{12} & x \in[4,8] .\end{cases}
$$

We can show that $S$ is a contractive-like mapping and it is not a contraction mapping. Also, zero is the common fixed point of $T$ and $S$.

Now, using $T$ and $S$, we show that our iterative algorithm (1.2) has a better rate of convergence. Set $\alpha_{n}=\beta_{n}=\gamma_{n}=\frac{n}{n+1}$ for each $n \in \mathbb{N}$. Then, we get the following tables and graphs with the initial value 4.5 .

\section{TABLE 1}

\begin{tabular}{|c|c|c|}
\hline No. of Iter. & Thounthong Iter. & Proposed Iter. \\
\hline 1 & 4.5 & 4.5 \\
2 & 0.3678125 & 0.048125 \\
3 & 0.0199193930041152 & 0.000332716049382716 \\
4 & 0.000771876478909465 & $1.66358024691358 \times 10^{-6}$ \\
5 & 0.0000234650449588477 & $6.65432098765432 \times 10^{-9}$ \\
6 & $5.92661372160198 \times 10^{-7}$ & $2.25918305136412 \times 10^{-11}$ \\
7 & $1.29245103899658 \times 10^{-8}$ & $6.76218056190622 \times 10^{-14}$ \\
8 & $2.50075813014183 \times 10^{-10}$ & $1.83142390218293 \times 10^{-16}$ \\
9 & $4.38023356677181 \times 10^{-12}$ & $4.57227915222625 \times 10^{-19}$ \\
10 & $7.05217604250261 \times 10^{-14}$ & $1.06686513551946 \times 10^{-21}$ \\
\hline
\end{tabular}

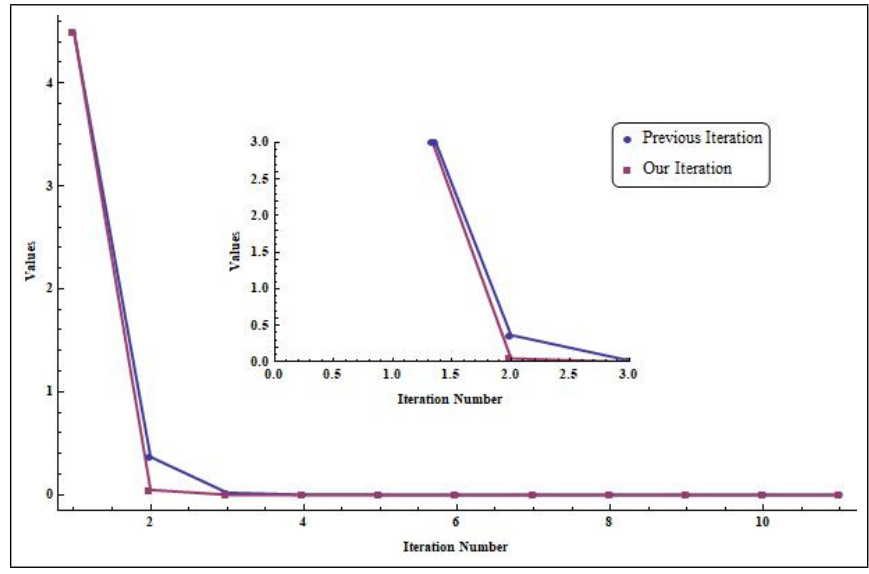

FIGURE 1. Graph corresponding to Table 1.

Clearly, the proposed iterative method converges faster than the previous one. 


\section{CONVERGENCE ANALYSIS}

Lemma 4.5. Let $(X, d)$ be a complete $C A T(1)$ space and $K$ be a non-empty, closed and convex subset of $X$. Let $T$ and $S$ be two nonexpansive mappings on $K$ such that $F:=F(T) \cap F(S) \neq \emptyset$, where $F(T)$ and $F(S)$ be two sets of fixed point for mappings $T$ and $S$ respectively. Let $\left\{x_{n}\right\}$ be sequence defined by (1.2) for $x_{0} \in K$ such that $d\left(x_{0}, F\right) \leq \frac{\pi}{4}$. Then there exists a unique point $p \in F$ such that $d\left(y_{n}, p\right) \leq d\left(z_{n}, p\right) \leq d\left(x_{n}, p\right) \leq \frac{\pi}{4}$ for all $n \geq 0$.

Proof. By the paper of Piatek in [22] and Lemma 2.1 there exists a unique point $p \in F$ such that $d\left(x_{0}, p\right)=d\left(x_{0}, F\right)$. By the condition of nonexpansive mapping $d\left(T x_{0}, p\right) \leq d\left(x_{0}, p\right) \leq$ $\frac{\pi}{4}$ and $B_{\frac{\pi}{4}}(p)$ is convex, we get

$$
\begin{aligned}
d\left(y_{0}, p\right) & =d\left(T\left(\left(1-\beta_{0}\right) z_{0} \oplus \beta_{0} S z_{0}\right), p\right) \\
& \leq d\left(z_{0}, p\right)=d\left(\left(1-\alpha_{0}\right) x_{0} \oplus \alpha_{0} T x_{0}, p\right) \leq d\left(x_{0}, p\right) \leq \frac{\pi}{4} .
\end{aligned}
$$

Suppose that $d\left(y_{k}, p\right) \leq d\left(z_{k}, p\right) \leq d\left(x_{k}, p\right) \leq \frac{\pi}{4}$. Since $B_{\frac{\pi}{4}}(p)$ is convex, we get

$$
\begin{aligned}
d\left(x_{k+1}, p\right) & =d\left(S y_{k}, p\right) \\
& \leq d\left(y_{k}, p\right) \leq d\left(x_{k}, p\right) \leq \frac{\pi}{4}
\end{aligned}
$$

and

$$
\begin{aligned}
d\left(y_{k+1}, p\right) & =d\left(T\left(\left(1-\beta_{k+1}\right) z_{k+1} \oplus \beta_{k+1} S z_{k+1}\right), p\right) \\
& \leq d\left(z_{k+1}, p\right)=d\left(\left(1-\alpha_{k+1}\right) x_{k+1} \oplus \alpha_{k+1} T x_{k+1}, p\right) \leq d\left(x_{k+1}, p\right) \leq \frac{\pi}{4} .
\end{aligned}
$$

It follows that $d\left(y_{k+1}, p\right) \leq d\left(z_{k+1}, p\right) \leq d\left(x_{k+1}, p\right) \leq \frac{\pi}{4}$. By mathematical induction, we get $d\left(y_{n}, p\right) \leq d\left(z_{n}, p\right) \leq d\left(x_{n}, p\right) \leq \frac{\pi}{4}$ for all $n \geq 0$. This completes the proof.

Lemma 4.6. Let $(X, d)$ be a complete $C A T(1)$ space and $K$ be a non-empty, closed and convex subset of $X$. Let $T$ and $S$ be two nonexpansive mappings on $K$ such that $F:=F(T) \cap F(S) \neq \emptyset$. Let $\left\{x_{n}\right\}$ be sequence defined by (1.2) for $x_{0} \in K$ such that $d\left(x_{0}, F\right) \leq \frac{\pi}{4}$, then

(i) $\lim _{n \rightarrow \infty} d\left(x_{n}, p\right)$ exist for $p \in F$;

(ii) $\lim _{n \rightarrow \infty} d\left(T x_{n}, x_{n}\right)=0=\lim _{n \rightarrow \infty} d\left(S x_{n}, x_{n}\right)$.

Proof. From Lemma 2.2 and Lemma 4.5, there exist $p \in F$ and $M>0$ such that

$$
\begin{aligned}
d^{2}\left(x_{n+1}, p\right) & =d^{2}\left(S\left(T\left(\left(1-\beta_{n}\right) z_{n} \oplus \beta_{n} S z_{n}\right)\right), p\right) \\
& \leq d^{2}\left(T\left(\left(1-\beta_{n}\right) z_{n} \oplus \beta_{n} S z_{n}\right), p\right) \\
& \leq\left(1-\beta_{n}\right) d^{2}\left(z_{n}, p\right)+\beta_{n} d^{2}\left(S z_{n}, p\right)-\frac{M}{2} \beta_{n}\left(1-\beta_{n}\right) d^{2}\left(z_{n}, S z_{n}\right) \\
& \leq d^{2}\left(z_{n}, p\right)-\frac{M}{2} \beta_{n}\left(1-\beta_{n}\right) d^{2}\left(z_{n}, S z_{n}\right) \leq d^{2}\left(z_{n}, p\right)
\end{aligned}
$$

and

$$
\begin{aligned}
d^{2}\left(z_{n}, p\right) & =d^{2}\left(\left(1-\alpha_{n}\right) x_{n} \oplus \alpha_{n} T x_{n}, p\right) \\
& \leq\left(1-\alpha_{n}\right) d^{2}\left(x_{n}, p\right)+\alpha_{n} d^{2}\left(T x_{n}, p\right)-\frac{M}{2} \alpha_{n}\left(1-\alpha_{n}\right) d^{2}\left(x_{n}, T x_{n}\right) \\
& \leq d^{2}\left(x_{n}, p\right)-\frac{M}{2} \alpha_{n}\left(1-\alpha_{n}\right) d^{2}\left(x_{n}, T x_{n}\right) \leq d^{2}\left(x_{n}, p\right)
\end{aligned}
$$

By (4.5) and (4.6), we get

$$
d^{2}\left(x_{n+1}, p\right) \leq d^{2}\left(x_{n}, p\right) .
$$


Therefore, $d\left(x_{n+1}, p\right) \leq d\left(x_{n}, p\right)$ which gives that $\lim _{n \rightarrow \infty} d\left(x_{n}, p\right)$ exist.

Next, we prove $(i i)$. Let

$$
\lim _{n \rightarrow \infty} d\left(x_{n}, p\right)=c .
$$

Then, from (4.5) and (4.6), we have $d\left(x_{n+1}, p\right) \leq d\left(z_{n}, p\right) \leq d\left(x_{n}, p\right)$ which on using (4.7) gives

$$
\lim _{n \rightarrow \infty} d\left(z_{n}, p\right)=c
$$

Now, from (4.6) we see that

$$
d^{2}\left(z_{n}, p\right) \leq d^{2}\left(x_{n}, p\right)-\frac{M}{2} \alpha_{n}\left(1-\alpha_{n}\right) d^{2}\left(x_{n}, T x_{n}\right)
$$

thus,

$$
d^{2}\left(x_{n}, T x_{n}\right) \leq \frac{2}{\alpha_{n}\left(1-\alpha_{n}\right) M}\left[d^{2}\left(x_{n}, p\right)-d^{2}\left(z_{n}, p\right)\right] .
$$

By (4.7) and (4.8), we get

$$
\lim _{n \rightarrow \infty} d\left(x_{n}, T x_{n}\right)=0 .
$$

Also, from (4.5) we get

$$
d^{2}\left(x_{n+1}, p\right) \leq d^{2}\left(z_{n}, p\right)-\frac{M}{2} \beta_{n}\left(1-\beta_{n}\right) d^{2}\left(z_{n}, S z_{n}\right)
$$

which gives

$$
d^{2}\left(z_{n}, S z_{n}\right) \leq \frac{2}{\beta_{n}\left(1-\beta_{n}\right) M}\left[d^{2}\left(z_{n}, p\right)-d^{2}\left(x_{n+1}, p\right)\right] .
$$

Thus, on using (4.7) and (4.8) we get

$$
\lim _{n \rightarrow \infty} d\left(z_{n}, S z_{n}\right)=0 .
$$

Now,

$$
d\left(z_{n}, x_{n}\right)=d\left(\left(1-\alpha_{n}\right) x_{n} \oplus \alpha_{n} T x_{n}, x_{n}\right)=\alpha_{n} d\left(T x_{n}, x_{n}\right) .
$$

So, on using (4.9) we have

$$
\lim _{n \rightarrow \infty} d\left(z_{n}, x_{n}\right)=0
$$

Consider

$$
\begin{aligned}
d\left(x_{n}, S x_{n}\right) & \leq d\left(x_{n}, z_{n}\right)+d\left(z_{n}, S z_{n}\right)+d\left(S z_{n}, S x_{n}\right) \\
& \leq d\left(x_{n}, z_{n}\right)+d\left(z_{n}, S z_{n}\right)+d\left(z_{n}, x_{n}\right)
\end{aligned}
$$

which on using (4.10) and (4.11) yields

$$
\lim _{n \rightarrow \infty} d\left(S x_{n}, x_{n}\right)=0 .
$$

This completes the proof.

Theorem 4.2. Let $(X, d)$ be a complete $C A T(\kappa)$ space and let $K$ be a non-empty, closed and convex subset of $X$. Let $T$ and $S$ be two nonexpansive mappings on $K$ such that $F:=F(T) \cap F(S) \neq \emptyset$.. Let $\left\{x_{n}\right\}$ be sequence defined by (1.2) for $x_{0} \in K$ such that $d\left(x_{0}, F\right) \leq \frac{\pi}{4}$, then $\left\{x_{n}\right\} \Delta-$ converges to a point in $F$. 
Proof. Without loss of generality, we assume that $\kappa=1$. Set $F_{0}=F \cap B_{\frac{\pi}{2}}\left(x_{0}\right)$. Let $q \in F_{0}$. Since the open ball $B_{\frac{\pi}{2}}(q) \in K$ with radius $r<\frac{\pi}{2}$ is convex, we get

$$
d\left(z_{0}, q\right)=d\left(\left(1-\alpha_{0}\right) x_{0}+\alpha_{0} T x_{0}, q\right) \leq d\left(x_{0}, q\right) .
$$

Also,

$$
d\left(x_{1}, q\right)=d\left(S\left(T\left(\left(1-\beta_{0}\right) z_{0}+\beta_{0} S z_{0}\right)\right), q\right) \leq d\left(z_{0}, q\right) \leq d\left(x_{0}, q\right)
$$

By mathematical induction, we can prove that

$$
d\left(x_{n+1}, q\right) \leq d\left(x_{n}, q\right) \leq d\left(x_{0}, q\right) .
$$

for all $n \geq 0$. Thus, a sequence $\left\{x_{n}\right\}$ is a Fejer monotone sequence with respect to $F_{0}$. Let $p \in F$ such that $d\left(x_{0}, p\right) \leq \frac{\pi}{4}$. Then, $p \in F_{0}$. Also, we have

$$
d\left(x_{n+1}, p\right) \leq d\left(x_{n}, p\right) \leq d\left(x_{0}, p\right) \leq \frac{\pi}{4}
$$

for all $n \geq 0$. This proves that $r\left(\left\{x_{n}\right\}\right)<\frac{\pi}{4}$. From Lemma 2.3, let $x \in k$ be a $\Delta-$ cluster point of $\left\{x_{n}\right\}$. Then there exists a subsequence $\left\{x_{n_{k}}\right\}$ of $\left\{x_{n}\right\}$ which $\Delta$-converges to $x$. By (4.8), we obtain

$$
r\left(p,\left\{x_{n_{k}}\right\}\right) \leq d\left(x_{0}, p\right) \leq \frac{\pi}{4}
$$

From Lemma 2.4, we get

$$
d\left(x, x_{0}\right) \leq d(x, p)+d\left(x_{0}, p\right) \leq \liminf _{k \rightarrow \infty} d\left(x_{n_{k}}, p\right)+d\left(x_{0}, p\right)<\frac{\pi}{2} .
$$

This implies that $x \in B_{\frac{\pi}{2}}\left(x_{0}\right)$. From Lemma 4.6, we get

$$
\begin{aligned}
\limsup _{k \rightarrow \infty} d\left(T x, x_{n_{k}}\right) & \leq \limsup _{k \rightarrow \infty} d\left(T x, T x_{n_{k}}\right)+\limsup _{k \rightarrow \infty} d\left(T x_{n_{k}}, x_{n_{k}}\right) \\
& =\limsup _{k \rightarrow \infty} d\left(T x, T x_{n_{k}}\right)
\end{aligned}
$$

and

$$
\begin{aligned}
\limsup _{k \rightarrow \infty} d\left(S x, x_{n_{k}}\right) & \leq \limsup _{k \rightarrow \infty} d\left(S x, S x_{n_{k}}\right)+\limsup _{k \rightarrow \infty} d\left(S x, x_{n_{k}}\right) \\
& =\limsup _{k \rightarrow \infty} d\left(S x, S x_{n_{k}}\right)
\end{aligned}
$$

Thus, $T x, S x \in A\left(\left\{x_{n_{k}}\right\}\right)$ and $T x=x=S x$. Hence $x \in F_{0}$. By Lemma 3, we thus complete the proof.

If $\kappa=0$, we obtain the following result in $\operatorname{CAT}(0)$ spaces.

Corollary 4.1. Let $(X, d)$ be a complete $C A T(0)$ space and let $K$ be a non-empty, closed and convex subset of $X$. Let $T$ and $S$ be two nonexpansive mappings of $K$ such that $F:=F(T) \cap F(S) \neq \emptyset$. Let $\left\{x_{n}\right\}$ be sequence defined by (1.2) for $x_{0} \in K$, then $\left\{x_{n}\right\} \Delta$-converges to a point in $F$.

Theorem 4.3. Let $(X, d)$ be a complete $C A T(\kappa)$ space and let $K$ be a non-empty, closed and convex subset of $X$. Let $T$ and $S$ be two nonexpansive mappings of $K$ such that $F:=F(T) \cap F(S) \neq \emptyset$. Suppose that $T, S$ are semi-compact for some $m \in \mathbb{N}$. If $\left\{x_{n}\right\}$ is defined by (1.2) for $x_{0} \in K$ such that $d\left(x_{0}, F\right) \leq \frac{\pi}{4}$, then $\left\{x_{n}\right\}$ converges strongly to a point in $F$.

Proof. By Lemma 4.6, we get

$$
\lim _{n \rightarrow \infty} d\left(x_{n}, T x_{n}\right)=0
$$

and

$$
\lim _{n \rightarrow \infty} d\left(x_{n}, S x_{n}\right)=0
$$


Thus, $\liminf _{n \rightarrow \infty} d\left(x_{n}, F\right)=0$. Since $d\left(x_{n+1}, p\right) \leq d\left(x_{n}, p\right) \forall p \in F$,

it follows that

$$
d\left(x_{n+1}, F\right) \leq d\left(x_{n}, F\right) .
$$

Hence, $\lim _{n \rightarrow \infty} d\left(x_{n}, F\right)$ exists and $\lim _{n \rightarrow \infty} d\left(x_{n}, F\right)=0$. That is, $\left\{x_{n}\right\}$ is an approximate common fixed point sequence for $T$ and $S$. By Definition 2, there exist a subsequence $\left\{x_{n_{j}}\right\}$ of $\left\{x_{n}\right\}$ and $p \in K$ such that $\lim _{j \rightarrow \infty} x_{n_{j}}=p$. Next, we get

$$
\begin{aligned}
d(T p, S p) \leq & d(T p, p)+d(S p, p) \\
\leq & d\left(T p, T x_{n_{j}}\right)+d\left(T x_{n_{j}}, x_{n_{j}}\right)+d\left(x_{n_{j}}, p\right) \\
& +d\left(S p, S x_{n_{j}}\right)+d\left(S x_{n_{j}}, x_{n_{j}}\right)+d\left(x_{n_{j}}, p\right) \\
\rightarrow & 0 \text { as } j \rightarrow \infty .
\end{aligned}
$$

That is, $p \in F$. From Lemma 4.6, we have $\lim _{n \rightarrow \infty} d\left(x_{n}, p\right)$ exists, thus $p$ is the strong limit of the sequence $\left\{x_{n}\right\}$ itself. This completes the proof.

\section{NUMERICAL EXAMPLES}

Some non trivial examples are presented in this section to demonstrate the efficiency of the proposed iteration process. All the codes are written in Mathlab2020a running on a new surface pro, Core(TM)i5-7300U CPU, Intel(R) with $2.7 \mathrm{GHz}$ and memory 8 GB RAM.

5.1. m-sphere $\mathbb{S}^{m}$. The m-sphere $\mathbb{S}^{m}$ is defined by

$$
\left\{x=\left(x_{1}, \ldots, x_{m+1}\right) \in \mathbb{R}^{m+1}:\langle x, x\rangle=1\right\}
$$

where $\langle\cdot, \cdot\rangle$ denotes the Euclidean scalar product.

The normalized geodesic $c: \mathbb{R} \rightarrow \mathbb{S}^{m}$ beginning from $x \in \mathbb{S}^{m}$ is denoted by

$$
c(l)=(\cos l) x+(\sin l) v, \quad \forall l \in \mathbb{R},
$$

where $v \in T_{x} \mathbb{S}^{m}$ is a unit vector; which respect distance $d$ on $\mathbb{S}^{m}$ such that

$$
d(x, y)=\arccos (\langle x, y\rangle)
$$

for all $x, y \in \mathbb{S}^{m}$.

Example 5.2. [28, Example 1] Let $K=\mathbb{S}^{3}$ and $T, S: K \rightarrow K$ be two nonexpansive mappings which are defined by

$$
T x=S x=\left(x_{1},-x_{2},-x_{3},-x_{4}\right), \quad \forall x=\left(x_{1}, x_{2}, x_{3}, x_{4}\right) \in \mathbb{S}^{3} .
$$

Then $F(T) \cap F(S)=\{(1,0,0,0)\}$.

Now, Thounthong iteration (1.1) can be written in the form

$$
\begin{aligned}
& w_{n}=\left(\cos \left(\left(1-c_{n}\right) r\left(x_{n}, x_{n}\right)\right)\right) x_{n}+\left(\sin \left(\left(1-c_{n}\right) r\left(x_{n}, x_{n}\right)\right)\right) U\left(x_{n}, x_{n}\right), \\
& y_{n}=\left(\cos \left(\left(1-b_{n}\right) \bar{r}\left(w_{n}, w_{n}\right)\right)\right) w_{n}+\left(\sin \left(\left(1-b_{n}\right) \bar{r}\left(w_{n}, w_{n}\right)\right)\right) U\left(w_{n}, w_{n}\right), \\
& x_{n+1}=\left(\cos \left(\left(1-a_{n}\right) \bar{r}\left(T w_{n}, y_{n}\right)\right)\right) T w_{n}+\left(\sin \left(\left(1-a_{n}\right) \bar{r}\left(T w_{n}, y_{n}\right)\right)\right) \bar{U}\left(T w_{n}, y_{n}\right),
\end{aligned}
$$

and proposed iteration (1.2) can be written in the form

$$
\begin{aligned}
& z_{n}=\left(\cos \left(\left(1-b_{n}\right) r\left(x_{n}, x_{n}\right)\right)\right) x_{n}+\left(\sin \left(\left(1-b_{n}\right) r\left(x_{n}, x_{n}\right)\right)\right) U\left(x_{n}, x_{n}\right), \\
& x_{n+1}=T\left(S\left(\left(\cos \left(\left(1-a_{n}\right) \bar{r}\left(z_{n}, z_{n}\right)\right)\right) z_{n}+\left(\sin \left(\left(1-a_{n}\right) \bar{r}\left(z_{n}, z_{n}\right)\right)\right) U\left(z_{n}, z_{n}\right)\right)\right),
\end{aligned}
$$

for all $n \geq 1$, where 


$$
\begin{aligned}
& r(x, y)=\arccos (\langle x, T y\rangle), \quad \bar{r}(x, y)=\arccos (\langle x, S y\rangle), \\
& U(x, y)=\frac{T y-\langle x, T y\rangle x}{\sqrt{1-\langle x, T y\rangle^{2}}}, \quad \bar{U}(x, y)=\frac{S y-\langle x, S y\rangle x}{\sqrt{1-\langle x, S y\rangle^{2}}},
\end{aligned}
$$

Setting control parameters $a_{n}=\frac{n}{20 n+1}, b_{n}=\frac{n}{10 n+1}, c_{n}=\frac{n}{30 n+1}$ and stop criterion as $\left\|x_{n}-F(T) \cap F(S)\right\| \leq 10^{-7}$.

We test different initial values as

Choice $1: x_{1}=(0.9,0.3,0.3,0.1)$;

Choice $2: x_{1}=(0.8,0.4,0.4,0.2)$;

Choice $3: x_{1}=(0.5,0.5,0.5,0.5)$;

Choice $4: x_{1}=(0.7,0.5,0.5,0.1)$.

TABLE 2. Numerical results for different initial values of Example 5.2

\begin{tabular}{|ll|ccccccc|}
\hline & & $\begin{array}{c}\text { Mann } \\
\text { iter. }\end{array}$ & $\begin{array}{c}\text { Ishikawa } \\
\text { iter. }\end{array}$ & $\begin{array}{c}\text { Noor } \\
\text { iter. }\end{array}$ & $\begin{array}{c}\text { S } \\
\text { iter. }\end{array}$ & $\begin{array}{c}\text { Abbas } \\
\text { iter. }\end{array}$ & $\begin{array}{c}\text { Thounthong } \\
\text { iter. }\end{array}$ & $\begin{array}{c}\text { Proposed } \\
\text { iter. }\end{array}$ \\
\hline \multirow{2}{*}{ Choice 1 } & No. of Iter. & 148 & 75 & 105 & 47 & 96 & 44 & 41 \\
& Time & 3.236 & 0.875 & 2.438 & 0.641 & 1.016 & 0.302 & 0.114 \\
\cline { 2 - 9 } Choice 2 & No. of Iter. & 151 & 76 & 101 & 48 & 98 & 40 & 37 \\
& Time & 3.911 & 0.866 & 2.104 & 0.525 & 1.875 & 0.214 & 0.159 \\
\cline { 2 - 9 } Choice 3 & No. of Iter. & 155 & 79 & 106 & 49 & 101 & 41 & 38 \\
& Time & 2.841 & 0.618 & 2.016 & 0.321 & 1.844 & 0.202 & 0.116 \\
\cline { 2 - 9 } Choice 4 & No. of Iter. & 153 & 77 & 99 & 48 & 99 & 40 & 37 \\
& Time & 2.996 & 1.645 & 2.016 & 0.611 & 2.025 & 0.209 & 0.102 \\
\hline
\end{tabular}

FIGURE 2. Behavior convergence of algorithms corresponding to Table 2
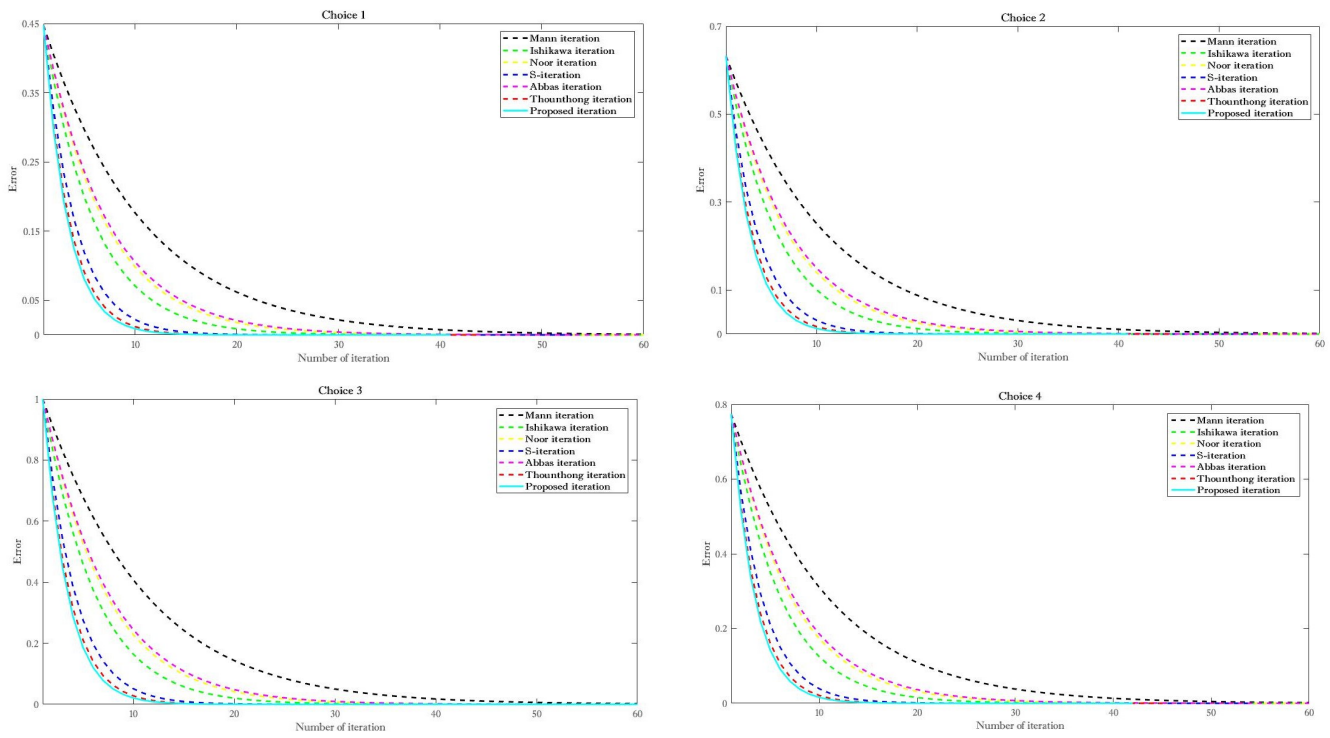
5.2. Hyperbolic $m$-space $\mathbb{H}^{m}$. The hyperbolic $m$-space $\mathbb{H}^{m}$ is defined by

$$
\left\{x:=\left(x_{1}, x_{2}, x_{3}, \ldots, x_{m+1}\right) \in \mathbb{R}^{m+1}:\langle x, x\rangle=-1 \text { and } x_{m+1} \geq 1\right\},
$$

where

$$
\langle x, y\rangle=\sum_{i=1}^{m} x_{i} y_{i}-x_{m+1} y_{m+1}, \quad \forall x=\left(x_{i}\right), y=\left(y_{i}\right) \in \mathbb{R}^{m+1} .
$$

The normalized geodesic $c: \mathbb{R} \rightarrow \mathbb{H}^{m}$ beginning from $x \in \mathbb{H}^{m}$ is denoted by

$$
c(l)=(\cosh l) x+(\sinh l) v, \quad \forall l \in \mathbb{R},
$$

where $v \in T_{x} \mathbb{H}^{m}$ be a unit vector; which respect distance $d$ on $\mathbb{H}^{m}$ such that

$$
d(x, y)=\operatorname{arccosh}(-\langle x, y\rangle),
$$

for all $x, y \in \mathbb{H}^{m}$.

Example 5.3. [28, Example 2] Let $K=\mathbb{H}^{3}$ and $T, S: K \rightarrow K$ be two nonexpansive mappings which are defined by

$$
T x=S x=\left(-x_{1},-x_{2},-x_{3}, x_{4}\right), \quad \forall x=\left(x_{1}, x_{2}, x_{3}, x_{4}\right) \in \mathbb{H}^{3}
$$

Then $F(T) \cap F(S)=\{(0,0,0,1)\}$.

Now, Thounthong iteration (1.1) can be written in the form

$$
\begin{aligned}
& w_{n}=\left(\cosh \left(\left(1-c_{n}\right) r\left(x_{n}, x_{n}\right)\right)\right) x_{n}+\left(\sinh \left(\left(1-c_{n}\right) r\left(x_{n}, x_{n}\right)\right)\right) U\left(x_{n}, x_{n}\right), \\
& y_{n}=\left(\cosh \left(\left(1-b_{n}\right) \bar{r}\left(w_{n}, w_{n}\right)\right)\right) w_{n}+\left(\sinh \left(\left(1-b_{n}\right) \bar{r}\left(w_{n}, w_{n}\right)\right)\right) U\left(w_{n}, w_{n}\right), \\
& x_{n+1}=\left(\cosh \left(\left(1-a_{n}\right) \bar{r}\left(T w_{n}, y_{n}\right)\right)\right) T w_{n}+\left(\sinh \left(\left(1-a_{n}\right) \bar{r}\left(T w_{n}, y_{n}\right)\right)\right) \bar{U}\left(T w_{n}, y_{n}\right),
\end{aligned}
$$

and the proposed iteration process (1.2) can be written in the form

$$
\begin{aligned}
& w_{n}=\left(\cosh \left(\left(1-b_{n}\right) r\left(x_{n}, x_{n}\right)\right)\right) x_{n}+\left(\sinh \left(\left(1-b_{n}\right) r\left(x_{n}, x_{n}\right)\right)\right) U\left(x_{n}, x_{n}\right), \\
& x_{n+1}=T\left(S\left(\left(\cosh \left(\left(1-a_{n}\right) \bar{r}\left(w_{n}, w_{n}\right)\right)\right) w_{n}+\left(\sinh \left(\left(1-a_{n}\right) \bar{r}\left(w_{n}, w_{n}\right)\right)\right) U\left(w_{n}, w_{n}\right)\right)\right), \forall n \geq 1,
\end{aligned}
$$

for all $n \geq 1$, where

$$
\begin{aligned}
& r(x, y)=\operatorname{arccosh}(-\langle x, T y\rangle), \quad \bar{r}(x, y)=\operatorname{arccosh}(-\langle x, S y\rangle), \\
& U(x, y)=\frac{T y-\langle x, T y\rangle x}{\sqrt{1-\langle x, T y\rangle^{2}}}, \quad \bar{U}(x, y)=\frac{S y-\langle x, S y\rangle x}{\sqrt{1-\langle x, S y\rangle^{2}}},
\end{aligned}
$$

Setting control parameters $a_{n}=\frac{1}{10 n+1}+0.9, b_{n}=\frac{1}{20 n+1}+0.8, c_{n}=\frac{1}{90 n+1}+0.2$ and stop criterion as $\left\|x_{n}-F(T) \cap F(S)\right\| \leq 10^{-7}$.

We test different initial values as

Choice $1: x_{1}=(3,3,9,10)$;

Choice $2: x_{1}=(2,2,4,5)$;

Choice $3: x_{1}=(1,7,7,10)$;

Choice $4: x_{1}=(1,3,5,6)$. 
TABLE 3. Numerical results for different initial values of Example 5.3

\begin{tabular}{|ll|ccccccc|}
\hline & & $\begin{array}{c}\text { Mann } \\
\text { iter. }\end{array}$ & $\begin{array}{c}\text { Ishikawa } \\
\text { iter. }\end{array}$ & $\begin{array}{c}\text { Noor } \\
\text { iter. }\end{array}$ & $\begin{array}{c}\text { S } \\
\text { iter. }\end{array}$ & $\begin{array}{c}\text { Abbas } \\
\text { iter. }\end{array}$ & $\begin{array}{c}\text { Thounthong } \\
\text { iter. }\end{array}$ & $\begin{array}{c}\text { Proposed } \\
\text { iter. }\end{array}$ \\
\hline \multirow{2}{*}{ Choice 1 } & No. of Iter. & 83 & 231 & 300 & 417 & 58 & 33 & 29 \\
& Time & 0.994 & 2.816 & 3.022 & 4.178 & 0.777 & 0.412 & 0.109 \\
\cline { 2 - 10 } Choice 2 & No. of Iter. & 82 & 224 & 291 & 419 & 56 & 32 & 28 \\
& Time & 0.771 & 2.754 & 3.116 & 4.011 & 0.516 & 0.308 & 0.096 \\
\cline { 2 - 9 } Choice 3 & No. of Iter. & 83 & 231 & 300 & 417 & 58 & 33 & 29 \\
& Time & 0.987 & 0.2 .711 & 3.225 & 4.106 & 0.764 & 0.401 & 0.098 \\
\cline { 2 - 9 } Choice 4 & No. of Iter. & 82 & 230 & 299 & 415 & 58 & 32 & 29 \\
& Time & 0.896 & 2.566 & 3.011 & 4.238 & 0.711 & 0.398 & 0.086 \\
\hline
\end{tabular}

FIGURE 4. Behavior convergence of algorithms corresponding to Table 3
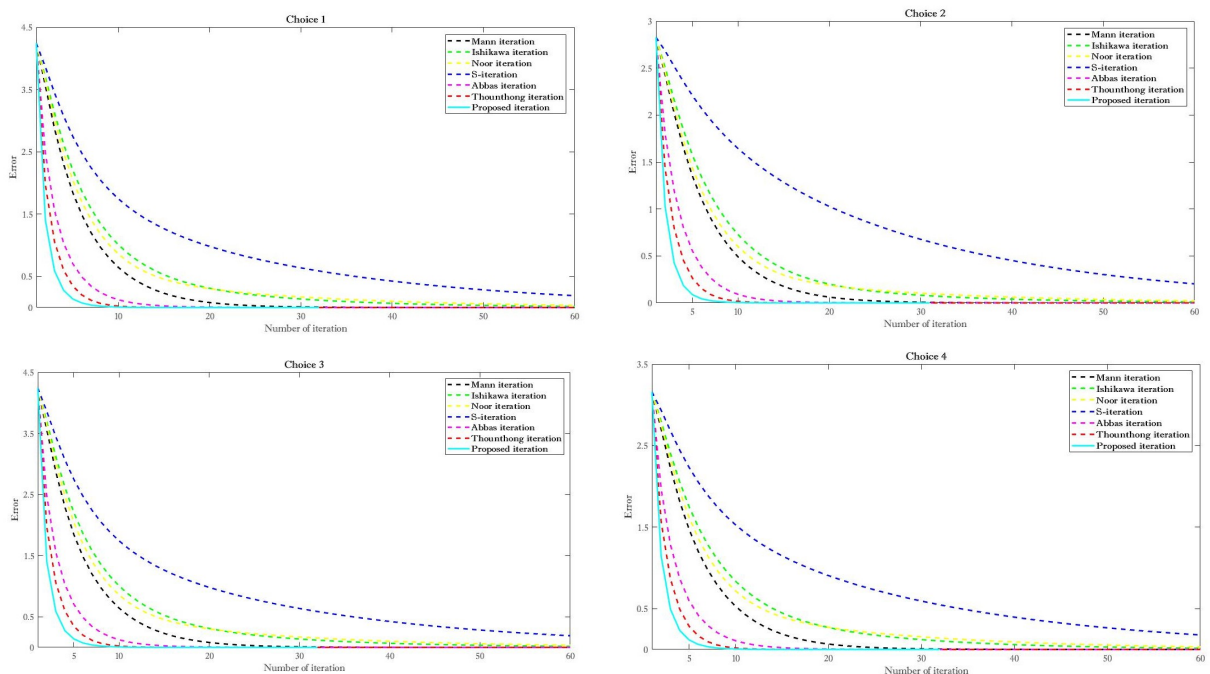

\section{CONCLUSIONS}

In this paper, we have obtained a new modified two step iteration process in the setting of CAT $(\kappa)$ spaces. With the help of to guarantee performance of our iteration process, we have shown that the proposed process (1.2) is having a better rate of convergence than number of existing iteration processes in the literature. Moreover, we have provided numerical of two non-trivial examples to show the efficiency of the proposed process (1.2) converges the fastest for a different set of initial values and number of iterations as well as CPU time at least in Tables 2 and 3. Also, Figures 2 and 4 of examples 5.2 and 5.3 are guarantee that the behavior convergence of the proposed algorithm better than existing iterations, respectively.

Acknowledgments. The project is under the support of SUT Research and Development Fund.

\section{REFERENCES}

[1] Banach, S., Sur les opérations dans les ensembles abstraits et leurs application aux équations intégrales, Fundam. Math., 3 (1922), 133-181

[2] Berinde, V., On the convergence of the Ishikawa iteration in the class of quasi contractive operators, Acta Math. Univ. Comenian., 73 (2004), 119-126 
[3] Berinde, V. Picard iteration converges faster than Mann iteration for a class of quasi contractive operators, Fixed Point Theory Appl., 2004 (2004), 97-105, doi:10.1155/S1687182004311058

[4] Bridson, M. R. and Haefliger, A., Metric Spaces of Non-positive Curvature, SpringerVerlag, Berlin, 1999

[5] Chaoha, P. and Phon-on, A., A note on fixed point sets in CAT(0) spaces, J. Math. Anal. Appl., 320 (2006), 983-987

[6] Dhompongsa, S., Kaewkhao, A. and Panyanak, B., Lim's theorems for multivalued mappings in CAT(0) spaces, J. Math. Anal. Appl., 312 (2005), 478-487

[7] Dhompongsa, S., Kirk, W. A. and Sims, B., Fixed points of uniformly lipschitzian mappings, Nonlinear Anal., 65 (2006), 762-772

[8] Espínola, R. and Fernández-León, A., CAT $(\kappa)$-spaces, weak convergence and fixed points, J. Math. Anal. Appl. 353 (2009), 410—427

[9] Gromov, M., Hyperbolic groups, In: Essays in group theory, Springer, New York, 8 (1987), 75-263

[10] He, J. S., Fang, D. H., Lopez, G. and Li, C., Mann's algorithm for nonexpansive mappings in $C A T(\kappa)$ spaces, Nonlinear Anal., 75 (2012), 445-452

[11] Imoru, C. O. and Olatinwo, M. O., On the stability of Picard and Mann iteration processes, Carpathian J. Math., 19 (2003), 155-160

[12] Kirk, W. A., Geodesic geometry and fixed point theory, In: Seminar of Mathematical Analysis (Malaga/Seville, 2002/2003). Colecc. Abierta. Universidad de Sevilla Secretariado de Publicaciones, Sevilla, 64, (2003), 195-225

[13] Kirk, W. A., Geodesic geometry and fixed point theory II, In: International Conference on Fixed Point Theory and Applications, Yokohama Publ., Yokohama (2004), 113-142

[14] Kirk, W. A. and Panyanak, B., A concept of convergence in geodesic spaces, Nonlinear Anal., 68 (2008), 3689-3696

[15] Leustean, L., A quadratic rate of asymptotic regularity for CAT(0) spaces, J. Math. Anal. Appl., 325 (2007), 386-399

[16] Lim, T. C., Remarks on some fixed point theorems, Proc. Amer. Math. Soc., 60 (1976), 179-182

[17] Ohta, S., Convexities of metric spaces, Geom. Dedic. 125 (2007), 225-250

[18] Panyanak, B., On total asymptotically nonexpansive mappings in CAT $(\kappa)$ spaces, J. Inequal. Appl., 336 (2014)

[19] Panyanak, B. and Laokul, T., On the Ishikawa iteration process in CAT(0) spaces, Bull. Iranian Math. Soc., 37 (2011), 185-197

[20] Panyanak, B., On the Ishikawa iteration process for multivalued mappings in some CAT $(\kappa)$ spaces, Fixed Point Theory Appl. 2014, 2014:1

[21] Pakkaranang, N., Kumam, P., Cholamjiak, P., Suparatulatorn, R. and Chaipunya, P., Proximal point algorithms involving fixed point iteration for nonexpansive mappings in CAT ( $\kappa)$ spaces, Carpathian J. Math., 34 (2018), 229-237

[22] Piatek, B., Halpern iteration in CAT $(\kappa)$ spaces, Acta Math. Sin., 27 (2011), 635-646

[23] Saejung, S., Halpern's iteration in CAT(0) spaces, Fixed Point Theory Appl., 2010 (2010), ArticleID 471781, 13 pp.

[24] Saluja, G. S., Postolache, M. and Kurdi, A., Convergence of three-step iterations for nearly asymptotically nonexpansive mappings in CAT $(\kappa)$ spaces, J. Inequal. Appl., 2015 (2015), ArticleID 156, 18 pp.

[25] Schu, J., Weak and strong convergence to fixed points of asymptotically nonexpansive mappings, Bull. Austral. Math. Soc., 43 (1991), 153-159

[26] Shahzad, N. and Markin, J., Invariant approximations for commuting mappings in CAT(0) and hyperconvex spaces, J. Math. Anal. Appl., 337 (2008), 1457-1464 
[27] Suparatulatorn, R. and Cholumjiak, P., The modified S-iteration process for nonexpansive mappings in CAT $(\kappa)$ spaces,Fixed Point Theory Appl., 2016 (2016), ArticleID 25, 12 pages, doi:10.1186/s13663-016-0515-6

[28] Thounthong, P., Pakkaranang, N., Saipara, P., Phairatchatniyom, P. and Kumam, P., Convergence analysis of modified iterative approaches in geodesic spaces with curvature bounded above, Math. Methods Appl. Sci., 42 (2019), 5929-5943

[29] Zamfirescu, T., Fix point theorems in metric spaces, Arch. Math., 23 (1972), 292-298, doi:10.1007/BF01304884

${ }^{1}$ MATHEMATICS ENGLiSH PROGRAM

FACULTY OF EDUCATION

Valaya Alongkorn Rajabhat University under the Royal Patronage

1 Moo 20 Phaholyothin Road, Klong Neung, Klong Luang, Pathumthani, 13180, Thailand

Email address: thanatpron.banevru.ac.th

${ }^{2}$ DEPARTMENT OF MATHEMATICS

JAmia Millia Islamia, NeW DELHI-110025, INDIA

Email address: c.garodia85egmail.com (C. Garodia)

Email address: izharuddin1@jmi.ac.in (I. Uddin)

${ }^{3}$ DEPARTMENT OF MATHEMATICS

FACULTY OF SCIENCE

King MONGKUT'S University OF TECHNOlOgy THONBURI (KMUTT)

126 PRACHA-UTHIt ROAD, BANG MOD, Thrung KHRU, BANGKOK 10140, THAilAnd

Email address: nuttapol.pakka@gmail.com

${ }^{4}$ SCHOOL OF MATHEMATICS

INSTITUTE OF SCIENCE

SuRANAREE UNIVERSity OF TECHNOLOGy, NAKHON RATCHASIMA 30000, THAilAND

Email address: panu.yesut.ac.th 